\title{
Morphological Processing Strategies: An Intervention for Spelling Difficulties in English Language
}

\author{
Dimitris Anastasiou \\ Assistant Professor in Special Education \\ Department of Elementary Education, School of Education, University of Western Macedonia, Florina, Greece \\ E-mail: anastasiou@uowm.gr
}

Eleni Griva (Corresponding author)

Assistant Professor in Teaching a Second/Foreign Language

Department of Elementary Education, School of Education, University of Western Macedonia, Florina, Greece

E-mail: egriva@uowm.gr; egriva@otenet.gr

Received: December 28, 2011

Accepted: January 29, 2012

Published: April 1, 2012

doi:10.5539/elt.v5n4p15

URL: http://dx.doi.org/10.5539/elt.v5n4p15

\begin{abstract}
The paper presents a descriptive account of a Morphological Processing Spelling Approach (MPSA), which substitutes a more conventional spelling instruction, proposed for developing primary school students' metamorphological knowledge and strategies in English as a foreign language. For the application of the MPSA, seven dictation texts were carefully designed by the researchers, each one including a specific morphemic pattern recycled in ten different words. They were implemented in the $6^{\text {th }}$ grade of an English primary school classroom during seven 45 minute sessions, carried out after the completion of every unit of the conventional English textbook. In this way, each dictation served as a recycling way of teaching inflexional and derivational morphemic patterns. In a guided participatory context, problem-solving spelling activities were performed in five basic steps, involving spellers, especially the struggling ones, into employing morphological processing strategies during sub- processes. It could serve as a supplementary strategy to learning to spell, a critical element of a comprehensive approach to spelling instruction, since MPSA is a flexible approach and can also incorporate the use of phonetic or visually-memory based spelling strategies.
\end{abstract}

Keywords: Intervention, Spelling, English language, Metamorhological training, MPSA approach

\section{Introduction}

Spelling is a difficult task for many elementary school students. Thus, teaching spelling, particularly to children facing spelling difficulties, is an important component of literacy instruction. Besides the social prestige surrounding high or low spelling performance, there are some other reasons related to schooling for explicit spelling instruction. First, difficulties in guessing the correct spelling may interfere with the execution of higher-order processes that could result into text writing constraints (Graham, 1999) and frustration. Second, spelling difficulties appear to be a persistent phenomenon. If these difficulties remain untreatable, it is quite possible to persist throughout the elementary school (Juel, 1988) and high school (Shankweiler, Lundquist, Dreyer, \& Dickinson, 1996).

Traditionally, spelling instruction in Greek elementary school has been based on teaching methods laying emphasis on visual memory for words; that is rote memorization (Goulandris, 1985; Graham, 1983; Templeton \& Morris, 2000).

However, for the last two decades the view of spelling as a visual memory activity has been replaced with spelling conceived as a complex task, which draws upon an individual's phonological awareness, knowledge of orthography (sound-symbol relationships, letter patterns and spelling regularities), knowledge of vocabulary, morphological awareness and visual memory skills (Arra, \& Aaron, 2001; Frith, 1980; Treiman, 1993). Furthermore, spelling is influenced by correlated skills such as reading performance (Caravolas, Hulme, \& Snowling, 2001; Ehri, 1987).

Recent empirical studies provided strong evidence that visual memory plays a minor role in spelling than that considered in the past, as for the last years spelling has been thought to involve primarily cognitive and 
psycholinguistic skills (Arra, \& Aaron, 2001; Bourassa, \& Treiman, 2001; Treiman, 1993). Although there has been substantial research providing evidence on the involvement of psycholinguistic skills, such as phonological and morphological processing, in spelling development, there has been a slight change in spelling instruction in the elementary classroom, where English is taught as a foreign language.

\section{The Conventional Spelling Instruction in the English Language Classroom}

In Greek schools, where English is taught as a foreign language for three hours per week, the conventional way of teaching and testing spelling is based, mainly, on the rote memorization; children are given lists of often unassociated words and have to memorize their spellings (Henry 1993). Flash cards, word walls and look-cover-write-check technique are some of the techniques that are used to assist the memorization of spellings (Goulandris, 1985).

Peters' $(1967,1970)$ look-cover-write-check technique, modified by Torbe (1970) by adding an intermediate stage of word pronunciation as children learn it (cited in Goulandris, 1985, p. 138), is the current basic method of memorization of spelling in either first or foreign language in Greek schools. It is a kind of 'whole word' technique which implies the importance of rote visual memory in spelling learning. The rationale behind this teaching method is that learning to spell is a simple matter of storing sequences of letters in a correct order in visual memory. The effective implementation of these techniques follows a 'test-study-test' cycle based on a 'trial and error' learning process. The study of word lists necessitates the individual concentration on the spelling target without leaving enough space in cooperative learning methods. However, implementing this technique in an inappropriate way could result into limited individualized teaching (all students study the same lists), or/and a disproportionate cost/benefit ratio in terms of spending time (much time is spent on low-frequency words), especially for struggling spellers (Allal, 1997).

An alternative way of teaching spelling is the phonetic transcription of either words in a spelling list or a text extract. More specifically, in the first case, the teacher dictates individual words in isolation, and students transcribe them phonetically. In the second case, 'dictation texts' are simple paragraphs selected from the student-book texts, which usually are delivered at the beginning of every class session. The dictation texts are drawn from literary sources, while their length and complexity vary according to students' grade. The teacher dictates the text and the students begin transcribing. Occasionally, a student can ask for a word or phrase to be repeated; the teacher generally repeats any word or phrase once, if requested. Then he/she reads aloud the dictation through a second time at normal speaking speed. After the dictation completion, the teacher either collects the notebooks to correct the errors in the classroom or, in some cases, he/she follows a peer-correction technique. The basic problem with this teaching method is that English orthography is an opaque one; phonetic transcription is a necessary strategy but an incomplete one for students' achieving spelling accuracy.

Both the aforementioned methods may have some useful aspects and elements. For example, phonetic transcription probably is helpful for promoting the phonological processing skills of the students in the first stages of spelling development. Rote memorization of word lists is necessary for learning the lexical aspects of spelling and for verb conjugation (Allal, 1997). If it is implemented properly, it is a good technique for developing a 'basic spelling vocabulary' (Graham, 1983), boosting the orthographic processing skills of the students.

However, both these methods do not contribute to the reflection on the orthographic structure of the words and they do not cover all the spectrum of psycholinguistic and cognitive skills involved in spelling performance. In addition, more teaching time is spent on checking out the learning outcome of dictation rather than on explicit and systematic teaching of spelling as well as on the intrinsic learning process. In such an instructional context, the way the students learn is not taken into consideration. Nevertheless, the basic aim of spelling is to make students be able to create orthographically correct text by themselves.

Alternative ways of teaching spelling in educational practice should be explored. It is necessary for the teachers to employ multiple strategy instruction in order to make students develop a greater repertoire of effective spelling strategies. Therefore, experimenting with new ways of spelling instruction, focused on developing awareness of morphological word structure, is of vital importance.

\section{English Orthography and Morphological Processing Strategies}

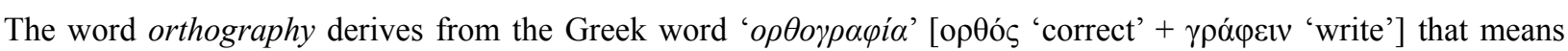
"correct writing". Orthography refers to the written clothing of the words of a specific language, and in the strict sense it is the standardized form of the spelling system. Orthography in an alphabetic script is primarily related to the orthographic rules of grapheme-phoneme correspondence and spelling patterns. In addition, it is related to other text conventions, such as the word separation, capitalization, hyphenation, punctuation (Coulmas, 1989; Jaffré, 1997; 
Perfetti, 1997; Venezky, 1999).

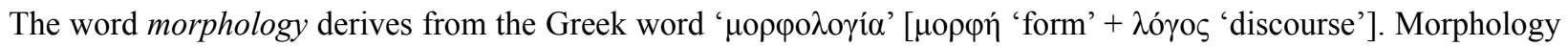
refers to an organizational level of language that deals with the morphemes, the smallest meaningful units of language which are distinguished into two major types: free and bound morphemes (Carstairs-McCarthy, 2002; Moats, 2000). Free morphemes can be individual words (e.g. eye, wife, believe). The well-known root morphemes, in teaching practice, are free morphemes, and more specifically content words (including nouns, verbs, adjectives and adverbs). Bound morphemes are meaningful units of words which can not be stand alone as words and must be combined with other morphemes. Bound morphemes can be either prefixes (e.g. de-, ex-, in-, intra-, sub-, un), or bound roots, usually Latin words (e.g. spect in aspect, spectacle, spectator, spectacular) that cannot be English words, or suffixes (-er, -or, -tion, -ness, -y, -ful, -able, -ly) (Bauer, 1988; Carstairs-McCarthy, 2002; Moats, 2000). Prefixes can change the meaning of a root but not its grammatical class (e.g. disappear, unhappy). Suffixes can change the meaning as well as the grammatical class of a root (e.g. colorful, cooking, cooker, boxes), providing information about the gender, number, grade and tense (e.g. actor, bunches, quicker, eating) (Arnbak \& Elbro, 2000; Bauer, 1988; Carstairs-McCarthy, 2002).

Morphological relations can be classified under three major categories: a) derivational morphology refers to lexical relations between content words (e.g. color and colorful, paint and painter) that contribute to formulating new words, b) inflectional morphology refers to grammatical relations between a word stem and grammatical suffixes within a single content word (e.g. tell, tells, telling), c) lexical compounding refers to the combination of free lexical morphemes to form a new word (e.g. sun-shine) (Ravid, \& Mashraki, 2007; Rispens, McBride-Chang, Reitsma, 2008). Lexical compounding or inflexions and derivations attached to a root morpheme may change the phonology of the root morpheme. For this reason, the morphological relations between words sharing the same root (e.g. magic and magician, omit and omission) often become less transparent, especially in oral language (Arnbak, \& Elbro, 2000).

Languages have been classified, on the grounds of morphology, under 4 basic types: analytic/isolating, agglutinative, inflectional and polysynthetic. In an 'inflectional' language, like English and Greek (Jaffré, 1997), the boundaries among morphemes are not clear; the morphemes can have more than one grammatical meaning e.g. the suffix -ing in the word swimming can mean a noun (surfing = the activity of surfing) or the continuous form of a verb (e.g. 'the father is surfing').

Morphological awareness refers to the ability to explicitly understand the morphological structure of spoken words; in other words, to recognize the meaningful components of words - that is, a word like 'help' has one discrete morpheme, 'helpful' has two, and 'helpfully' has three morphemes. Furthermore, morphological awareness can be considered as part of metalinguistic awareness, which is the ability to reflect on the structural features of spoken language (Gombert, 1992; Tunmer, \& Hoover, 1992). However, in English, morphological awareness is even a more complicated process, mainly because of a) the phonological changes resulted in root morphemes by derivations and inflexions (decide and decision, loaf and loaves) in oral language, and b) the unclear boundaries among morphemes (e.g. bake and baking, heavy and heavier) in written language.

In the previous decade, studies focused on the importance of morphological knowledge use in spelling tasks (Carlisle, 1987; Henry, 1993; Sénéchal, Basque, \& Leclaire, 2006) and the developmental changes in this use (Carlisle, 1987; Kemp, 2006; Walker, \& Hauerwas, 2006); correlational and longitudinal studies focused on strength and nature of relationship between spelling skills and morphological awareness in oral and written tasks (e.g. Muter, \& Snowling, 1997; Nunes, Bryant, \& Bindman, 1997, 2006).

Orthography in alphabetic systems varies according to the transparency of the relation between phonemes and graphemes. The English spelling system is basically alphabetic, however a deep or opaque one. It is based on the correspondences between phonemes and graphemes, but they are relatively inconsistent compared to other orthographies of alphabetic scripts like Finish (Müller, \& Brady, 2001), Serbo-Croatian (Lucatela, Lucatela, Carello, \& Turvey, 1999), Turkish (Öney, \& Durgunoğlu, 1997), and Italian (Cossu, Gugliotta, \& Marshall, 1995). As Towery (1979) has noted "the same letters often represent different sounds, and the same sounds often were expressed by different letters" (p. 26). That happens because English orthography, apart from phonological information carries a big amount of morphological and semantic information closely connected with the etymological origins of the words (Geva, \& Siegel, 2000; Müller, \& Brady, 2001). The dependence upon the morphological information at the expense of phonological information renders the English orthography a deep one (Coulmas, 1996).

The nature of English orthography probably has an effect on learning to spell. First, there is a great difficulty in encoding words in their written form. Learning to spell poses a greater challenge than learning to read, because of 
the lower consistency from sound to letter(s) than from letter(s) to sound (Caravolas, Hulme, \& Snowling, 2001; van Orden, 1997). In other words, the number of different spellings mapping a phoneme is more varied than the number of possible pronunciations for particular spellings; thus, the wider choice of elements in spelling contributes substantially to the greater difficulty of spelling compared to reading (Bosman \&; Holmes, \& Carruthers, 1998).

Second, there is the possibility that the orthography dictates specific spelling strategies which fit better in their inconsistencies and irregularities. Apparently, the break of the alphabetic code is the first and probably the most basic step, since it facilitates the way of forming orthographic representations. However, due to the students' difficulty in mastering spelling, they must discover the internal morphological structure of the words. Thus, spelling instruction should lead children to linguistic insight that underlies the internal structure of the words.

\section{The Morphological Processing Spelling Approach}

\subsection{Rationale and Purpose}

Morphological Processing Spelling Approach (MPSA) is a type of morphological processing strategies training embedded on the spelling branch of teaching English as a second/foreign language. MPSA provides explicit and systematic metamorphological instruction in word-level spelling skills, when students do dictation of a meaningful text. It aims at developing the students' knowledge of morphemic structure and analysis of words, as well as the knowledge of semantic relationships between morphemes and spelling patterns (orthomorphology).

The MPSA bases its rationale on the fact that difficulties in finding the correct spelling of many words, due to the inconsistency of alphabetic principle, could be overcome with the help of morphological analysis. The awareness of morphemes that compose the words can reduce the cognitive load of students by limiting the initial orthographic space of words. In this way the spelling of an unfamiliar word can be split into smaller meaningful blocks (morphemes). As a result, the choice of letters would be reduced to a smaller and meaningful orthographic space (e.g. root word). Consequently, the application of morphological processing strategies during the spelling process is a type of a problem-solving activity (from 'disappeared' to dis-appear-ed, there is successive reduction, i.e. how the word 'appear' is spelled).

The discovery of morphology by students learning English as a foreign language, especially for struggling spellers, is not a natural act, as morphemes are not always easily recognizable; on the contrary, sometimes, morphemes are embedded deeply in orthography. Thus, spelling instruction in upper elementary grades should be extended beyond training in phonological and orthographic skills. The need to use knowledge of morphology to spell words becomes increasingly important, since students of the sixth grade begin to spell words of greater length and complexity. Students should explicitly be taught how to segment and extract stems and affixes through discussion (Henry, 1993).

Overall, there is a consensus among researchers that morphological awareness and morphological processing strategies could be a teaching way for developing students' spelling, word recognition, and reading comprehension abilities. Nevertheless, there is another teaching methodology question: What is/are the best way(s) to teach morphological awareness and/or morphological processing strategies? Up to now, there is not a shred of evidence to answer this question. This is another reason why there is a need for conducting intervention studies in the authentic context of general or special education classrooms.

In Greek elemetary schools, following the traditional way of teaching, students are taught 'grammatical rules' referring to certain morphological relations. The question is whether this grammatical knowledge is situated to the particular learning situation of the 'grammar lesson' or it can be transferred to other more functional situations such as spelling and writing. Based on our experience, we can assert that students, especially the struggling ones, do not transfer big amount of this grammatical knowledge to more functional literacy situations.

By drawing students' attention to the inflexions, derivations and compound words, the principal aim of the MPSA is to help students, especially the struggling ones, develop morphological knowledge and morphological strategies through the spelling process. In other words, MPSA is a functional way of utilizing grammar rules in a more meaningful literacy context.

Thus, MPSA aims at providing opportunities for:

(a) systematic recycling of morphological patterns in a range of meaningful spelling contexts;

(b) student engagement in problem-solving spelling activities that allow them to employ morphological processing strategies;

(c) scaffolding students' morphological processing strategies.

4.2 Materials

A pilot implementation of Morphological Processing Spelling Approach (MPSA), in a $6^{\text {th }}$ grade English classroom 
of a Greek state primary school, was based on seven (7) dictation texts designed by the researchers in cooperation with the English language teacher. The syllabus and especially the specific morphological items highlighted in every of the seven units of the textbook as well as the language skill level of the particular group of students were taken into account for composing the relative texts (see Table1).

[Insert Table 1 here]

The texts were implemented during seven 45 minute sessions extended into two terms of a school year, a certain period needed for the completion of the seven units of the textbook. Guided spelling sessions involved planned instruction that was carefully matched and sequenced to meet the needs of the specific classroom. Purposeful written contexts were constructed in which students could apply, practice and integrate the knowledge gained in every unit. Several of the spelling words incorporated in the units of the textbook were included in the stories composed by the researchers and the English language teacher. The design of material was based on the language norms that those students had been learning. In addition, examples of the language aspects, the class dealt with, in terms of grammar, vocabulary, and spelling were included. Thus, these dictation texts could serve as a recycling way of teaching certain morphemic patterns, as it was carried out after completing every unit of the textbook.

Each dictation text included a specific morphemic pattern recycled in ten different words within the passage (see Table 2). Such patterns were the following: the $-s$ plural, the -ed ending for regular verbs, adjective suffixes, comparative degree suffixes, noun suffixes (-or, er), the ending -ing, morpheme that causes a change to the root word, for example the doubling of the end consonant (e.g. telling, stopping). The students had to be aware of and familiar with changes so as to avoid any kind of errors; they had to know how the plural of nouns forms -especially those which constitute exceptions the rule "add -es". Moreover, they had to be aware of the formation of the past tense of regular verbs and of certain phonological changes which normally take place when certain morphemes are added to certain root words (e.g. knife - knives).

[Insert Table 2 here]

\subsection{Procedure}

Each session included a complete spelling activity performed in five basic steps, each one focusing on a specific subprocess with a meaningful objective.

\subsubsection{Step 1: Pre- Dictation stage - Morphological Awareness Training (about 10 minutes)}

Before dictation, children were taught oral identification and segmentation of morphemic components of words. These activities were designed to help children draw their attention to morphemic units of words. More specifically, the teacher pronounced 3-4 words of interest and she prompted the students to find their common parts identifying the morphemic pattern(s), or to 'detect' the smaller words within a bigger compound one (session 5).

Typically, the teacher addressed such questions as the following:

- What is the common part of the words quicker and louder? (-er)

- What are the building blocks of quicker? (quick and - er)

After segmenting the words into their morphemic constituents, she asked question like these that are described by Hauewas \&Walker (2004, p. 174)

- What does quick mean?

- What about - er? (answer referring to comparative function)

- What about - est? (answer referring to superlative function)

Such questions pointed out the meanings carried out by small morphemes such as - er , - est, when they are linked to short adjectives and adverbs (morpho-semantics). Then, the teacher asked questions as following:

- What sounds did you hear in the word quicker? /k/, /w/, /i/, /k/, / e/, /r/?

- What does $/ \mathrm{k} /$ means?

These last questions aimed at students' understanding that morphemes are meaningful units, while phonemes are not; they are simply sound units, as Hauewas \& Walker (2004) highlighted.

Then, the teacher gave two or three examples on the board, modeled the variety of ortho-morphology (e.g. heavy heavier - heaviest) and/or phono-morphology (e.g. appeared - talked - flitted) of target phenomenon, and explained to the children how these orthographic or phonetic varieties were working.

Also, she clarified the purpose of writing the specific dictation text, and provided specific directions about the 
'fill-in the gap' process (through "drawing a bubble") to the students and made them conceive the purpose of this procedure. Next, the teacher-made passage was dictated by the teacher twice.

4.3.2 Step 2: $1^{\text {st }}$ Teacher Dictation - Highlighting Morpho-semantics and Morpho-orthographic Relations (about 15 minutes)

The teacher read the text in phrases with pauses between phrases; she stopped dictating after each phrase or meaningful unit containing the specific spelling pattern where the students allocated attention. She questioned the students how they spelled the specific word and asked them to justify their choice. The students had more opportunities to find the semantic relationships between base word and suffixes, and to develop their knowledge of modification rules when adding suffixes.

Students had time to participate in the process; when the student, who was asked to spell the word, was not able to spell it correctly, the teacher chose another student to try instead, especially a student who had difficulties in concentrating or needed a kind of guidance. The process went on - in a guided participatory context (Rogoff, 1990).

In case the students did not feel certain about writing any target spelling words, including the specific pattern, they were encouraged to leave a blank space - by drawing a bubble- and to continue with transcribing the dictation. They could have the opportunity to fill in the gap by possibly transcribing the root word or the suffix morpheme correctly during the second teacher dictating.

These interchanges between the teacher and the students facing spelling difficulties provided opportunities for scaffolding that could reduce students' frustration and uncertainty, and enabled them to build the bridge between what they had already known to what they were learning. There was a gradual 'decrease' in teacher's support, from session to session, when students seemed to manage well on their own.

4.3.3 Step 3: $2^{\text {nd }}$ Teacher Dictation- Reflection on the Spelling Patterns Corresponding to Analyzed Morphemes (about 10 minutes)

The teacher proceeded to reread the dictation text for a second time, at normal speed, and the students were encouraged to reflect on their work and make any last changes; they tried to seek the boundaries of morphemic units, to compare and contrast spelling patterns (e.g. -er and -est, telling and eating, -er and -or, ended and liked), to realize phonetic differences, and to reflect on the grammatical rules. They had also the opportunity to restore any missing parts with either inflections or derivations or compounds. Students were encouraged to be flexible about employing strategies, so that they could switch to another strategy if they faced problems in roots, for example a phonetic or visual-memory strategy.

\subsubsection{Step 4: Self-correction and Focus on Students with Spelling Difficulties (about 5 minutes)}

After the completion of teacher's dictating, the students were given five more minutes in order to check out what they had already written. In this way, they were provided with the opportunity to review and proofread their work, to focus on 'where' and 'why' they were making mistakes and to correct them. They checked out if they had forgotten to write any word or they had made any punctuation mistakes and thus they could make any appropriate additions or corrections. During this subprocess, there was a special concern for a small number of students with spelling difficulties who were grouped together.

\subsubsection{Step 5: Verbalizing Metamorphological Strategies Explicitly - Evaluation (about 5 minutes)}

In the end, the students, especially the struggling spellers, were encouraged to verbalize: a) the thinking path that they used when they came up with a specific dictation mistake, b) the processes they employed for choosing the spelling of unknown words based on the most common spelling patterns, c) the specific difficulties they encountered during the whole procedure and the ways they dealt with them. This technique made children enjoy the procedure, since they were given the opportunity of releasing themselves from 'failure fear', as well as they had the possibility of developing metamorphological strategies.

\section{Discussion}

The present paper aimed at outlining the rational for and the process of developing a new spelling approach (MPSA). MPSA focuses on the teaching of morphological processing strategies during the spelling process and aims at enhancing student metamorphological knowledge and strategies in order to improve students' spelling ability, especially those with spelling difficulties in the context of general classroom. The premise of this approach is that spelling is a language-based skill, and English orthography is an opaque one, mainly because morphology mediates between phonology and spelling encoding. The very nature of English orthography dictates the teaching of morphology as a way of spelling development. The teaching of morphology is not only an advanced approach for upper elementary students to enhance spelling development but it can also be a back-up spelling strategy when 
phonetic or orthographic strategies are unreliable, ambiguous or impractical. MPSA is intended to be part of spelling and English language program, but its usefulness can be extended beyond the English classroom; a variant form of this novel approach has been already tested in the Greek language classroom (Anastasiou, \& Bantouna, 2007).

MPSA implementation is based on dictation texts, designed by the researchers and an English language teacher, served as a recycling way of teaching the constituent morphemic patterns of words (inflexions, derivations, roots). These problem-solving spelling activities are carried out in five basic steps. In the first three steps students are trained to identify morphemic pattern(s), to focus on morphological awareness, to pay attention to morpho-semantic and morpho-orthographic relations and to compare and contrast spelling patterns. Segmenting and extracting roots and affixes, and connecting spelling patterns to affixes and roots give meaning to the memorization of orthography, systematizes language teaching and makes spelling a purposeful activity. In the last two steps of the MPSA, students, especially the struggling spellers, are provided with opportunities for self-correcting and verbalizing metamorphological strategies explicitly.

The effectiveness of the MPSA was evaluated by conducting a study with 23 Greek students assigned to the treatment group. A spelling test was used as a basic instrument, which was administered to the treatment group, consisted of 23 students, and to the control group, consisted of 25 students, before the intervention and after the intervention was completed. The results from the effectiveness study were presented in another edited paper (Griva \& Anastasiou, 2009). A brief description covering the main points of the results indicates that the students of the treatment class scored significantly better than the control group. Specifically, the post-test results showed that the metamorphological training yielded specific effects on targeted morpheme patterns (inflectional and derivational patterns) since the students of the treatment class scored significantly better than the control group. Besides, the MPSA approach seemed to work well both with the poor spellers and the total of the students (Griva \& Anastasiou, 2009).

\section{Conclusion}

In conclusion, MPSA is a specific approach to what to teach (morphological structure of words, connections between spelling and morphemic patterns, the close links between morphology and semantics), how to teach (structured language approach, explicit teaching, systematic teaching sequence, guided participatory context), and whom to teach (teaching emphasis on struggling spellers). Thus, morphological processing strategies can provide an in-depth knowledge of the spelling system, and help to overcome the spelling difficulties rising in the basic alphabetic level of phoneme-letter(s) correspondences. MPSA tries to systemize a certain sequence in order to make feasible the teaching of metamorphological strategies. However, it could serve as a supplementary strategy to learning to spell, not as a predominant one, a critical element of a comprehensive approach to spelling instruction, since MPSA is a flexible approach and can also incorporate the use of phonetic or visually-memory based spelling strategies.

\section{References}

Allal, L. (1997). Learning to spell in the classroom. In C. A. Perfetti, L. Rieben, \& M. Fayol (Eds.), Learning to spell: Research, theory and practice across languages (pp. 129-150). London: Lawrence Erlbaum.

Anastasiou, D., \& Bantouna, A. (2007). The guided participated spelling method as a way of teaching support for students with learning disabilities in the regular classroom. In E. Makri-Botsari (Ed.), Themata diaxeirisis provlimaton scholikis taxis (pp. 38-52). Athens: Pedagogical Institute (in Greek).

Arra, C. T., \& Aaron, P. G. (2001). Effects of psycholinguistic instruction on spelling performance. Psychology in the Schools, 38, 357-363. http://dx.doi.org/10.1002/pits.1024

Arnbak, E., \& Elbro, C. (2000). The effects of morphological awareness training on the reading and spelling skills of young dyslexics. Scandinavian Journal of Educational Research, 44, 229-251. http://dx.doi.org/10.1080/00313830050154485

Bauer, L. (1988). Introducing Linguistic Morphology. Edinburgh: Edinburgh University Press.

Bourassa, D. C., \& Treiman, R. (2001). Spelling development and disabilities: The importance of linguistic factors. Language, Speech, and Hearing Services in Schools, 32, 172-181. http://dx.doi.org/10.1044/0161-1461(2001/016)

Caravolas, M., Hulme, C., \& Snowling, M. J. (2001). The Foundations of Spelling Ability: Evidence from a 3-Year Longitudinal Study. Journal of Memory and Language, 45, 751-774. http://dx.doi.org/10.1006/jmla.2000.2785

Carlisle, J. F. (1987). The use of morphological knowledge in spelling derived forms by learning-disabled and normal students. Annals of Dyslexia, 37, 90-108. http://dx.doi.org/10.1007/BF02648061

Carstairs-McCarthy, A. (2002). An introduction to English Morphology: Words and their structure. Edinburgh: 
Edinburgh University Press.

Cossu, G., Gugliotta, M., \& Marshall, J. C. (1995). Acquisition of reading and written spelling in a transparent orthography: two non parallel processes. Reading and Writing: An Interdisciplinary Journal, 7, 9-22. http://dx.doi.org/10.1007/BF01026945

Coulmas, F. (1989). The writing systems of the world. Oxford: Blackwell.

Coulmas, F. (1996). The Blackwell Encyclopedia of writing systems. Oxford: Blackwell.

Egan, J., \& Pring, L. (2004). The processing of inflectional morphology: A comparison of children with and without dyslexia. Reading and Writing, 17, 567-591. http://dx.doi.org/10.1023/B:READ.0000044433.30864.23

Ehri, L. C. (1987). Learning to read and spell words. Journal of Reading Behavior, 19, 5-31.

Frith, U. (1980). Unexpected spelling problems. In U. Frith (Ed.), Cognitive processes in spelling (pp. 495-515). London: Academic Press.

Gombert, J. E. (1992). Metalinguistic development. Chicago: University of Chicago Press.

Goulandris, N. K. (1985). Extending the written language skill of children with Specific Learning Disabilities Supplementary teaching techniques. In M. Snowling (Ed.), Children's written language difficulties (pp. 134-145). London: Routledge.

Graham, S. (1983). Effective spelling instruction. The Elementary School Journal, 83, 560-567. http://dx.doi.org/10.1086/461334

Graham, S. (1999). Handwriting and spelling instruction for students with learning disabilities: A review. Learning Disability Quarterly, 22, 78-98. http://dx.doi.org/10.2307/1511268

Griva, E, \& Anastasiou, D. (2009). The Effectiveness and the Feasibility of Morphological Strategies Training on EFL Students with and without Spelling Difficulties. The International journal of writing research, 1(3), 199-223.

Hauerwas, L. B., \& Walker, J. (2004). What can children's spelling of running and jumped tell us about their need for spelling instruction? The Reading Teacher, 58, 168-176. http://dx.doi.org/10.1598/RT.58.2.5

Henry, M. K. (1993). Morphological structure: Latin and Greek roots and affixes as upper code strategies. Reading and Writing: An Interdisciplinary Journal, 5, 227-241. http://dx.doi.org/10.1007/BF01027486

Jaffré, J. P. (1997). From writing to orthography: The functions and limits of the notion of system. In C. A. Perfetti, L. Rieben, \& M. Fayol (Eds.), Learning to spell: Research, theory and practice across languages (pp. 3-20). London: Lawrence Erlbaum.

Juel, C. (1988). Learning to read and write: A Longitudinal study of 54 children from first through fourth grades. Journal of Educational Psychology, 80, 437-447. http://dx.doi.org/10.1037/0022-0663.80.4.437

Kemp, N. (2006). Children's spelling of base, inflected, and derived words: Links with morphological awareness. Reading and Writing, 19, 737-765. http://dx.doi.org/10.1007/s11145-006-9001-6

Lucatela, G., Lucatela, K., Carello, C., \& Turvey, M. T. (1999). Effects of frequency and phonological ambiguity on naming Serbo-Croatian words. European Journal of Cognitive Psychology, 11(1), 1-16. http://dx.doi.org/10.1080/713752303

Moats, L. C. (2000). Speech to print. Baltimore: Paul H. Brookes.

Müller, K., \& Brady S. (2001). Correlates of early reading performance in a transparent orthography. Reading and Writing: An Interdisciplinary Journal, 14, 757-799. http://dx.doi.org/10.1023/A:1012217704834

Muter, V., \& Snowling, M. J. (1997). Grammar and phonology predict spelling in middle childhood. Reading and Writing: An Interdisciplinary Journal, 9, 407-425. http://dx.doi.org/10.1023/A:1007947129554

Nunes, T., Bryant, P., \& Bindman, M. (1997). Learning to spell regular and irregular verbs. Reading and Writing: An Interdisciplinary Journal, 9, 427-449. http://dx.doi.org/10.1023/A:1007951213624

Nunes, T., Bryant, P., \& Bindman, M. (2006). The effects of learning to spell on children's awareness of morphology. Reading and Writing, 19, 767-787. http://dx.doi.org/10.1007/s11145-006-9025-y

Perfetti, C. A. (1997). The psycholinguistics of spelling and reading. In C. A. Perfetti, L. Rieben \& M. Fayol (Eds.), Learning to spell: Research, theory and practice across languages (pp. 21-38). London: Lawrence Erlbaum.

Ravid, D., \& Mashraki, Y. E. (2007). Prosodic reading, reading comprehension and morphological skills in Hebrew-speaking fourth graders. Journal of Research in Reading, 30, 140-156. 
http://dx.doi.org/10.1111/j.1467-9817.2007.00340.x

Rispens, J. E., McBride-Chang, C., \& Reitsma, P. (2008). Morphological awareness and early and advanced word recognition and spelling in Dutch. Reading and Writing, 21, 587-607. http://dx.doi.org/10.1007/s11145-007-9077-7

Rogoff, B. (1990). Apprenticeship in thinking: Cognitive development in social context. Oxford: Oxford University Press.

Sénéchal, M., Basque, M., \& Leclaire, T. (2006). Morphological knowledge as revealed in children's spelling accuracy and reports of spelling strategies. Journal of Experimental Child Psychology, 95, 231-234. PMid:16808925

Shankweiler, D., Lundquist, E., Dreyer, L. G., \& Dickinson, C. C. (1996). Reading and spelling difficulties in high school students: Causes and consequences. Reading and writing: An Interdisciplinary Journal, 8, 267-294.

Templeton, S., \& Morris, D. (2000). Spelling. In M. L. Kamil, P. B. Mosenthal, P. D. Pearson, \& R. Barr (Eds.), Handbook of reading research, Vol. 3 (pp. 525-543). Mahwah, NJ: Erlbaum.

Towery, G. M. (1979). Spelling instruction through the nineteen century. The English Journal, 68(4), 22-27. http://dx.doi.org/10.2307/815785

Treiman, R. (1993). Beginning to spell. A study of first-grade children. New York: Oxford University Press.

Tunmer, W., \& Hoover, W. (1992). Cognitive and linguistic factors in learning to read. In P. B. Gough, L. C. Erhi, \& R. Treiman (Eds.), Reading acquisition (pp. 175-214). Hillsdale, NJ: Erlbaum.

Venezky, R. (1999). The American way of spelling: The structure and origins of American English orthography. NY: The Guilford Press.

Walker, J., \& Hauerwas, L. B. (2006). Development of phonological, morphological, and orthographic knowledge in young spellers: The case of inflected verbs. Reading and writing, 19, 819-843. http://dx.doi.org/10.1007/s11145-006-9006-1

Table 1. A sample of a dictation text (Session 7)

Focus: the noun suffixes -er and -or

Title: The Brawns family

The Brawns are a very strange family. Tom, the father, is a writer. Jessica, the mother, is a counselor. Their daughter (Alice) is a famous runner and their son (Bob) is an actor. (Charlie), the grandfather is a signer and (Betty), the grandmother is a sales manager. They also have a butler, (Nick), whose wife is his helper. Their son (Billy) is an aviator in an airline company and their daughter is a painter.

Table 2. Morpheme patterns, words of training sessions, and total number of words in dictation text per session

\begin{tabular}{|c|c|c|}
\hline Session \& Morpheme patterns & Words of training sessions & $\begin{array}{c}\text { Number of words } \\
\text { in } \\
\text { dictation text }\end{array}$ \\
\hline $\begin{array}{l}\text { 1. Present Continuous Inflexion } \\
\text { (-ing) }\end{array}$ & $\begin{array}{l}\text { surfing, searching, preparing, composing, mewing, } \\
\text { crying, baking, telling, stopping, eating }\end{array}$ & 128 \\
\hline 2. Plural Inflexions (-s, -es, -ies) & $\begin{array}{l}\text { lobbies, pianos, melodies, memories, bunches, lilies, } \\
\text { bunnies, loaves, mangoes, peaches, knives }\end{array}$ & 59 \\
\hline $\begin{array}{l}\text { 3. Comparative and superlative } \\
\text { suffixes (-er, -ier, -iest) }\end{array}$ & $\begin{array}{l}\text { naughtier, perkiest, cutter, prettier, quicker, louder, } \\
\text { heavier, kindlier, loveliest, friendliest }\end{array}$ & 45 \\
\hline $\begin{array}{l}\text { 4. Regular Inflexion in simple } \\
\text { past (-ed) }\end{array}$ & $\begin{array}{l}\text { appeared, topped, flitted, grubbed, trotted, touched, } \\
\text { liked, ended, talked, disappeared }\end{array}$ & 80 \\
\hline 5. Noun suffixes (-tion, -sion) & $\begin{array}{l}\text { Mansion, attention, direction, pension, occasion, } \\
\text { description, division, decision, institution, confusion }\end{array}$ & 68 \\
\hline $\begin{array}{l}\text { 6. Adjective suffixes (-y, -ful, } \\
\text {-able) }\end{array}$ & $\begin{array}{l}\text { breezy, cozy, comfortable, colorful, cheerful, playful, } \\
\text { naughty, miserable, beautiful, lovable }\end{array}$ & 84 \\
\hline 7. Noun suffixes (-er, -or) & $\begin{array}{l}\text { writer, counselor, runner, actor, signer manager, butler, } \\
\text { helper, aviator, painter }\end{array}$ & 74 \\
\hline
\end{tabular}

